\title{
Penerapan HOTs Pada Media Pembelajaran Game Matematika Dengan Metode DGBL
}

\author{
Anugerah Bagus Wijaya ${ }^{\mathrm{a}, 1, *}$, Randi Octavian Andriyono ${ }^{\mathrm{a}, 2}$ \\ ${ }^{a}$ Teknik Informatika, Ilmu Komputer, Universitas Amikom Purwokerto, Indonesia \\ 1 anugerah@amikompurwokerto.ac.id*; ${ }^{2}$ randioctavianandriyono2126@ gmail.com; \\ * korenpondensi penulis
}

ARTICLE INFO

Article history

Menerima 5 Desember 2019

Revisi 7 Januari 2020

Diterima 3 Juni 2020

Kata Kunci

DGBL

HOTs

Game pembelajaran

Media pembelajaran

\begin{abstract}
Melalui hasil wawancara penulis dengan murid di SD Negeri 2 Kembangan diperoleh informasi bahwa murid yang kesulitan dalam pembelajaran dikelas pada matapelajaran Matamatika. Dalam dunia pendidikan banyak game edukasi yang sudah dibuat sebagai media pembelajaran untuk anak-anak. Digital Game Basic Learning (DGBL) adalah salah satu metode yang menggunakan teknologi game, sebuah game digital apa pun bisa dianggap sebagai media jika terdapat unsur pembelajaran didalamnya. Masih terdapat kesenjangan penting dalam literatur tentang DGBL, karena metode tersebut masih perlu penekanan pada hasil pembelajaran dalam lingkungan kelas yang lebih otentik, dalam hal ini adalah kajian dalam segi keterampilan berpikir penggunanya dalam proses memahami materi atau pembelajaranya. Higher-Order Thinking Skills (HOTs), adalah salah satu komponen utama dalam keterampilan berpikir kreatif dan kritis dan ini adalah tingkat tertinggi dalam hierarki proses kognitif. Penelitian ini fokus pada merancang dan membangun media pembelajaran game dengan metode DGBL dan pendekatan HOTs. Tahapan penelitian sistem Game yang akan digunakan sebagai media untuk pembelajaran Matamatika terdiri dari tiga tahap, yakni tahap, tahap pengumpulan data, tahap analisis dan pembahasan, metode pengembangan sistem yang penulis gunakan untuk mengembangan game edukasi ini adalah Digital Game Based Learning - Infrastructure Design (DGBL-ID). Berdasarkan hasil pengujian yang telah dilakukan dapat disimpulkan bahwa game edukasi pembelajaran Matematika yang dibangun, dapat memberikan pengetahuan dan semangat belajar matematika pada siswa..
\end{abstract}

This is an open access article under the CC-BY-SA 4.0 license.

\section{Pendahuluan}

Proses belajar mengajar merupakan suatu kegiatan melaksanakan kurikulum suatu lembaga pendidikan, agar tercapai tujuan pendidikan. Tujuan pendidikan addalah mengantarkan peserta didik menuju pada perubahan-perubahan tingkah lakubaik intelektual, moral, maupun sosial agar dapat hidup mandiri sebagai individu dan makhluk sosial. Dalam mencapai tujuan tersebut peserta didik berinteraksi dengan lingkungan belajar yang diatur guru melalui proses pembelajaran [1].

Pendidikan adalah usaha sadar dan terencana untuk mewujudkan suasana belajar dan proses pembelajaran agar peserta didik secara aktif mengembangkan potensi dirinya untuk memiliki kekuatan spiritual keagamaan, pengendalian diri, kepribadian, kecerdasan, akhlak mulia, serta ketrampilan yang diperlukan dirinya, masyarakat, bangsa dan negara [2].

Proses pembelajaran pada satuan pendidikan diselenggarakan secara interaktif, inspiratif, menyenangkan, menantang, memotivasi peserta didik untuk berpartisipasi aktif, serta memberikan 
ruang yang cukup bagi prakarsa, kreativitas, dan kemandirian sesuai dengan bakat, minat, dan perkembangan fisik serta psikologis peserta didik [2].

Berdasarkan hasil wawancara dengan sumber Ibu Andy Yati selaku guru kelas 4 di SD Negeri 2 Kembangan, diperoleh informasi bahwa dalam proses pembelajaran yang telah dilaksanakan belumlah optimal salah satunya seperti media pendukung pembelajaran yang dapat meningkatkan minat belajar siswa. Hal ini dikarenakan dalam proses pembelajaran masih konvensional yaitu hanya dengan metode menulis dan membaca saja, sehingga murid kurang bersemangat dalam belajar.

Melalui hasil wawancara penulis dengan murid di SD Negeri 2 Kembangan diperoleh informasi bahwa banyak para murid yang kesulitan dalam pembelajaran dikelas.

Table 1. Mata Pelajaran yang tidak disukai

\begin{tabular}{cccc}
\hline \multirow{2}{*}{ No } & & Matapelajaran & \\
\cline { 2 - 4 } & Kurang di minati & Jumlah & Presentase \\
\hline 1 & Matematika $^{\mathrm{a}}$ & 15 & $83 \%$ \\
\hline 2 & Bahasa Jawa & 2 & $11 \%$ \\
\hline 3 & PKN & 1 & $6 \%$ \\
\hline
\end{tabular}

. Tabel 1. menunjukan bahwa mata pelajaran yang tidak disukai oleh siswa kelas 4 SD Negeri 2 Kembangan adalah mata pelajaran Matematika dilihat dari besarnya nilai presentase yang didapat adalah $83 \%$.

Matematika yang sebagai ilmu universal mendasari perkembangan teknologi modern yang mempunyai peran penting dalam memajuan daya pikir manusia. Seiring perkembangan sains dan teknologi yang sangat pesat, dunia pendidikan pun perlu mengadakan inovasi atau pembaharuan dalam berbagai bidang termasuk dalam strategi pelaksanaan pembelajaran. Oleh karena itu, pendidikan adalah masalah yang menarik untuk terus dikaji dan terus dikembangkan [3].

Perkembangan ilmu pengetahuan dan teknologi semakin mendorong upaya-upaya pembaharuan dalam pemanfaatan hasil-hasil teknologi dalam proses belajar. Para guru dituntut agar mampu menggunakan alat-alat yang dapat disediakan oleh sekolah, dan tidak tertutup kemungkinan bahwa alat - alat tesebut sesuai dengan perkembangan dan tuntutan zaman. Disamping dapat mengggunakan alat-aat yang tersedia, guru juga dituntut untuk mengembangkan ketrampilan membuat media pembelajaran yang akan digunakannya apabila media itu belum tersedia [4].

Penerapan teknologi juga diperlukan dalam sebuah pendidikan yang berkaitan dengan pembelajaran, yang mampu membangun semangat anak dalam belajar yang interaktif dan menarik, baik dalam penjelasan materi maupun pemberian soal seperti pilihan ganda, uraian, diskusi, dan sebagainya. Dengan memanfaatkan teknologi yang ada, akan dilakukan pengujian perancangan pembelajaran dengan pemanfaatan media teknologi pada SD Negeri 2 Kembangan yang berada di Jalan Raya Kembangan Bukateja, Kecamatan Bukateja, Kabupaten Purbalingga.

Dalam dunia pendidikan banyak game edukasi yang sudah dibuat sebagai media pembelajaran untuk anak-anak dengan tujuan bisa mengajarkan dasar pendidikan seperti menulis, menggambar, membaca, dan lain-lain. Pendekatan pendidikan pada anak-anak dengan game cukup efektif dengan sistem pembelajaran yang nyaman menarik dan mudah dimengerti [5].

Digital Game Basic Learning (DGBL) atau pembelajaran berbasis game digital adalah salah satu metode yang menggunakan teknologi game, sebuah game digital apa pun bisa dianggap sebagai media jika terdapat unsur pembelajaran didalamnya [6]. Dalam sebuah Game pemain mampu belajar dan berfikir secara langsung melalui tindakan yang dilakukan oleh pemain didalam game. Permainan edukasi dapat digunakan sebagai alternatif untuk meningkatkan pembelajaran Matematika dalam pengalaman yang menghibur. Dengan menerapkan metode DGBL, sebuah pembelajaran bukan hanya menarik namun juga memotifasi karena bentuk medianya sebuah game yang di dalamnya menggabungkan permasalah yang ada didunia nyata kedalam bentuk permainan yang menarik [7]. 
Sementara DGBL telah digunakan selama beberapa dekade, penerapan game untuk mengembangkan pengetahuan, beberapa peneliti berpendapat bahwa penelitian secara empiris membuktikan keefektifan permainan digital dalam pembelajaran masih kurang [6]. Masih terdapat kesenjangan penting dalam literatur tentang DGBL, karena metode tersebut masif perlu penekanan pada hasil pembelajaran dalam lingkungan kelas yang lebih otentik [8]. Dalam hal ini media pembelajaran game masih perlu di kaji dalam segi keterampilan berpikir penggunanya dalam proses memahami materi atau pembelajaranya.

Higher-Order Thinking Skills (HOTs), adalah salah satu komponen utama dalam keterampilan berpikir kreatif dan kritis dan ini adalah tingkat tertinggi dalam hierarki proses kognitif [9]. HOTs melibatkan keterampilan kognitif, yaitu keterampilan untuk menganalisis, mensintesis, mengevaluasi, dan menghasilkan ide.

Item-item dari HOTs akan menilai keterampilan kognitif dengan menganalisis, mengevaluasi, dan menciptakan. Item tersebut juga dapat berupa keterampilan kognitif dalam situasi baru untuk menyelesaikan masalah kehidupan sehari-hari. Oleh karena itu, butir-butir HOTs menguji kemampuan siswa untuk menerapkan pengetahuan, keterampilan, dan nilai-nilai dalam membuat penalaran dan refleksi untuk pemecahan masalah, pengambilan keputusan, inovatif, dan mampu menciptakan sesuatu.

Berdasarkan permasalahan yang telah dijelaskan maka dapat disimpulkan game edukasi memiliki peran penting dalam proses pembelajaran. Dengan menerapkan game edukasi pada pembelajaran Matematika, diharapkan dapat memotifasi belajar pada siswa. Oleh karena itu, penulis berniat membuat game edukasi menggunakan metode DGBL dan penerapan HOTs pada media pembelajaran geme diharapkan benar-benar mampu meningkatkan keterampilan kognitif melalui media game yang bertujuan untuk memudahkan proses pekerjaan guru dan orang tua dalam meningkatkan minat belajar matematika pada siswa.

\section{Tinjauan Pustaka}

\subsection{Digital Games Based Learning (DGBL)}

Definisi dari game adalah permainan atau aktivitas yang biasanya dilakukan untuk bersenangsenang yang dijadikan sebagai hiburan dan pembelajaran dari aspek kehidupan dan imajinasi, yang membatasi perilaku pemain-pemain dalam mengikuti peraturan yang ada pada game. Game adalah penghubung yang sangat kuat untuk pembelajaran karena mereka membuat game sesuai dengan keadaan yang sebenarnya [10].

Banyak video game yang ada, dan dikategorikan berdasarkan kenis genre. Berikut adalah merupakan daftar genre permainan yang sering di jumpai. Banyak kategori game yang saling berhubungan sehingga menciptakan gabungan dari banyak genre dalam satu game menurut Scoot Roger [11]: Action (Tindakan/Aksi), Role Playing Game (RPG), Third Person Shooter (TPS), Strategy. Simulation (Simulasi), Tycoon, Racing (Balapan), Arcade, Fighting (Pertarungan), Sports (Olahraga), Real Life, Musical, Puzzle.

Game edukasi memiliki tujuan untuk menunjang proses belajar mengajar dengan kegiatan yang menyenangkan dan lebih kreatif [12]. Status game, instruksi, dan tools yang disediakan oleh game akan membimbing pemain secara aktif untuk menggali informasi sehingga dapat memperkaya pengetahuan dan strategi saat bermain [13].

Media DGBL adalah aplikasi perangkat lunak yang digunakan untuk mendukung pembelajaran dengan memanfaatkan game [14]. Digital Game Based Learning merupakan metode pembelajaran yang menggabungkan konten pendidikan atau prinsip prinsip belajar dengan game yang bertujuan untuk menarik siswa untuk belajar [15]. Model pengembangan (DGBL) terdiri dari 5 fase yang harus diselesaikan sebelum dilanjutkan ke fase berikutnya, fase -fase tersebut yaitu analysis phase, design phase, development phase, quality assurance, dan implementation and evaluation. Di samping pembangkitan motivasi, game juga mempunyai beberapa aspek yang lebih unggul dibandingkan metode pembelajaran konvensional [16]. 


\subsection{Higher-Order Thinking Skills (HOTs)}

Higher-Order Thinking Skills (HOTs), adalah salah satu komponen utama dalam keterampilan berpikir kreatif dan kritis dan ini adalah tingkat tertinggi dalam hierarki proses kognitif [9]. HOTs terjadi ketika seseorang mendapat informasi baru, menyimpan, mengatur, dan mengaitkannya dengan pengetahuan yang ada dan kemudian meneruskan informasi untuk mencapai objek tertentu atau solusi dari suatu masalah..

HOTs melibatkan keterampilan kognitif, yaitu keterampilan untuk menganalisis, mensintesis, mengevaluasi, dan menghasilkan ide baru. Dibutuhkan lebih dari sekadar menghafal fakta (memori hafalan) seperti robot yang diprogram tetapi tidak bisa berpikir dengan sendirinya. HOTs membuat orang menggunakan fakta dan membuat koneksi antara fakta atau konsep lain, mengelola untuk mengkategorikan, memanipulasi mereka dan menerapkannya untuk solusi baru untuk situasi lain [6].

Untuk merangsang pemikiran siswa, tanya jawab dapat digunakan sebagai alat untuk mendorong siswa untuk berpikir di luar kotak pemikiran normal mereka. Siswa yang terlibat dalam proses pertanyaan akan dapat mengklarifikasi pemikiran mereka, keluar dengan ide-ide baru dan meningkatkan keterampilan pemecahan masalah [10].

Siswa dapat menerapkan dan menggunakan pengetahuan dalam situasi baru, menganalisis dan menyampaikan ide ke komponen, untuk memahami hubungan antara komponen dan dapat membuat penilaian dan keputusan berdasarkan kriteria tertentu. Selain itu, siswa juga dapat memikirkan ideide baru dan cara-cara baru dengan menggunakan informasi tersebut.

\section{Metode}

\subsection{Objek Penelitian}

Penelitian ini dilakukan di SD Negeri 2 Kembangan, JL. Raya Kembangan, Kab. Purbalingga, Provinsi Jawa Tengah, pada mirid-murid kelas 4. Penelitian ini akan dilakukan selama tiga bulan, terhitung dari awal bulan April 2019 sampai dengan akhir Juni 2019.

\subsection{Pengumpulan Data}

- Observasi (observation) penelitian ini mengumpulkan data dan informasi yang diperlukan dan melakukan pengamatan secara langsung pada siswa kelas 4 SD Negeri 2 Kembangan"

- Wawancara peneliti ini silakukan kepada guru dan siswa kelas 4 yaitu mencari permasalahan atau kendala matapelajaran yang kurang diminati atau terkendala dalam pembelajaranya, sehingga di temukan sumber masalah yaitu pada matapelajaran Matamatika..

- Studi Pustaka dilakukan dengan dengan cara mempelajari buku-buku pendukung dan sumber lain seperti Browsing melalui internet yang digunakan seagai literatur yang dapat mendukung dalam penelitian ini.

\subsection{Pengembangan Sistem}

Metode pengembangan yang digunakan dalam penelitian ini adalah metode Digital Game Based Learning. Metode penelitian ini dipilih karena cocok untuk penelitian ini, sehingga media pembelajaran ini mampu memotifasi siswa kelas 4. Berikut ini adalah metode DGBL: 


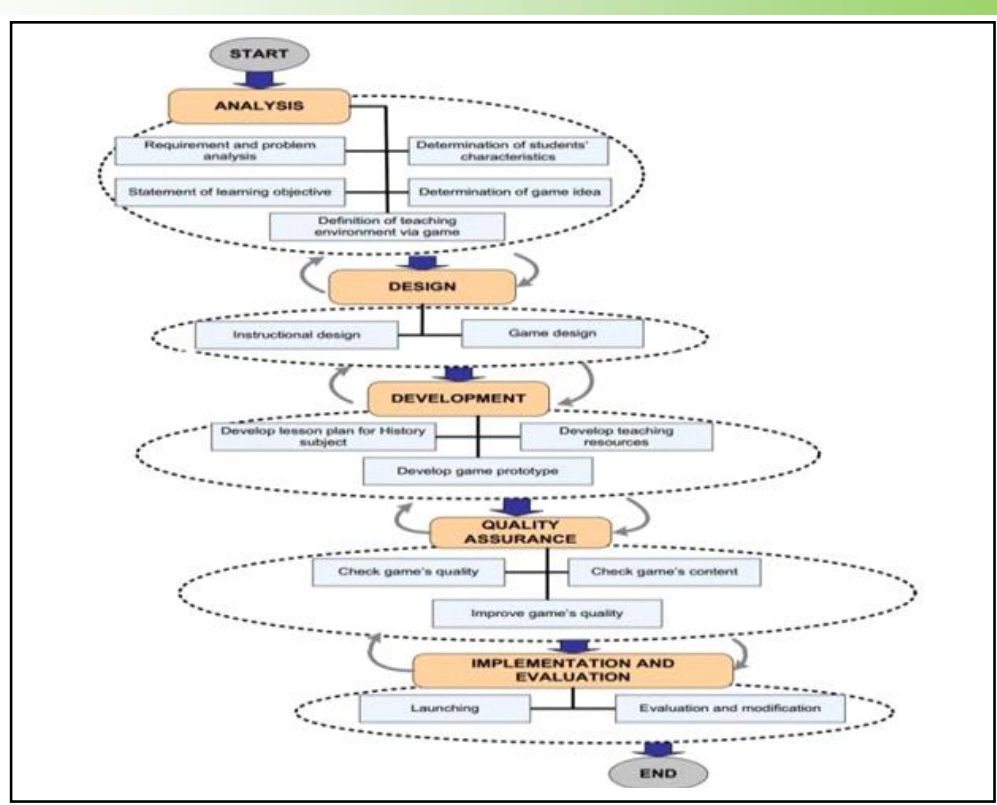

Fig. 1. Digital Game Base Learning [15]

\section{Hasil dan Pembahasan}

Aplikasi game Matematika ini penulis kembangkan menggunakan metode DGBL-ID, dengan menggunakan metode ini pengembang dan pihak SD N 2 Kembangan (Client) dapat bekerja sama agar aplikasi tersebut sesuai dengan yang diharapkan.

\subsection{Analysis}

Tahap analisis meliputi proses penentuan tujuan pembelajaran, analisis pembelajaran serta masalah dan analisis kebutuhan. Permasalahan yang dihadapi oleh peserta didik dalam belajar.

\section{- Requirement and problem analysis}

Berdasarkan hasil wawancara, terdapat permasalahan pada pembelajaran matematika yang seringkali membuat siswa-siswi merasa kesulitan serta dari hasil UTS mata pelajaran Matematika diperoleh rata-rata terendah.Dari permasalahan sulitnya mata pelajaran Matematika yang muncul, mengakibatkan turunnya semangat belajar pada siswa-siswi yang menyebabkan kebosanan pada mata pelajaran Matematika. Dengan adanya permasalahan tersebut diperlukan penanganan pemanfaatan media pembelajaran pada mata pelajaran Matematika yang lebih menarik dan interaktif.

\section{- Determination of students characteristics}

Diperolehnya data karakter siswa-siswi SD Negeri 2 Kembangan berdasarkan hasil wawancara yang diberikan.

Table 2. Karakteristik siswa

\begin{tabular}{cccc}
\hline \multirow{2}{*}{ No } & \multicolumn{3}{c}{ Karakteristik siswa SD N 2 Kembangan } \\
\cline { 2 - 4 } & Memiliki media elektroni Hand Phone dirumah & Ya & Tidak \\
\hline 1 & Sering Belajar melalui perangkat Hand Phone & 18 & 0 \\
\hline 2 & $\begin{array}{c}\text { Cenderung belajar melalui menggunakan media } \\
\text { elektronik lebih menarik daripada buku }\end{array}$ & 14 & 4 \\
\hline 3 & $\begin{array}{c}\text { Apakah orangtua mengijinkan selalu belajar melalui } \\
\text { media elektronik Hand Phone }\end{array}$ & 18 & 0 \\
\hline 4 & &
\end{tabular}

- Statement of learning objective 
Memberikan pelajaran tentang materi Matematika kelas IV sesuai dengan capaian kompetensi dasar yang digunakan di SD Negeri 2 Kembangan.

- Determination of game idea

Ide dari game ini adalah membuat historis perjalanan seorang anak laki-laki yang pintar, dimana dia selalu membantu permasalahan warga-warga sekitar dengan kemampuan Matematikanya dan mendapatkan imbalan berupa skor dari keberhasilan membantu setiap warga yang dia temui. Konsep permainan nantinya pemain akan berperan menjadi anak laki laki tersbut yang kemudian menjalankan sebuah misi untuk menyelesaikan sebuah masalah

- Definition of teaching environment via game

Platform game ini menyesuaikan dengan karakteristik siswa dimana Hand Phone Smartphone android sebagai Platform game yang akan digunakan untuk menjalankan game ini.

\subsection{Design}

Pada tahapan ini mendesain game media pembelajaran, penulis melakukan perancangan dengan melalui 2 fase:.

\section{- Instructional Design}

Instructional Design ini berdasarkan kompetensi inti dan indikator pencapaian dasar pelajaran Matematika kelas VI Sekolah Dasar

- Game Design

Higher-Order Thinking Skills (HOTs) melibatkan keterampilan kognitif, yaitu keterampilan untuk remembering, understanding, applying, analyzing, evaluating, dan creating. Penerapan HOTs di terapkan pada desain pemainan seperti berikut.

Table 3. Penerapan HOTs pada desain Permainan

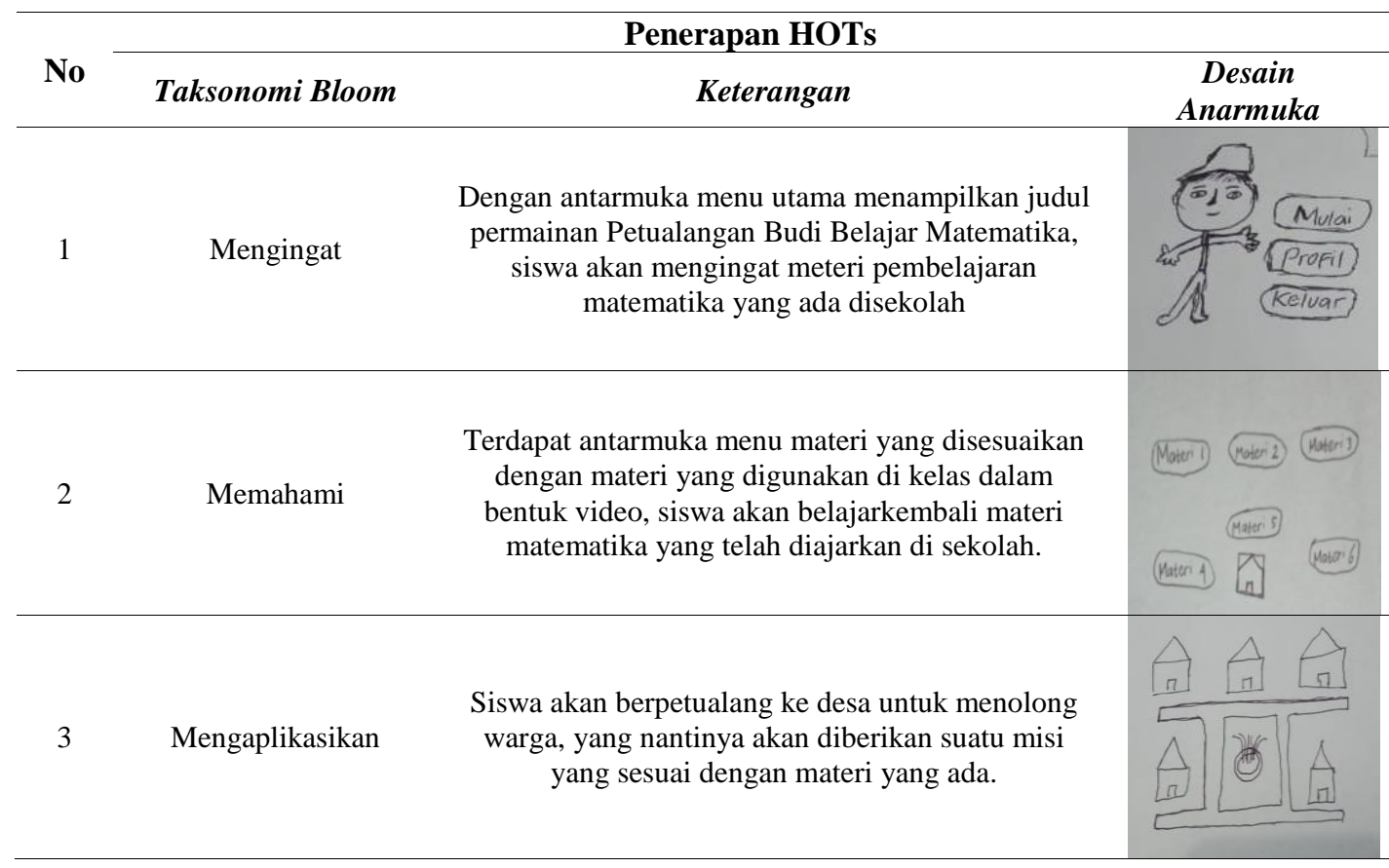




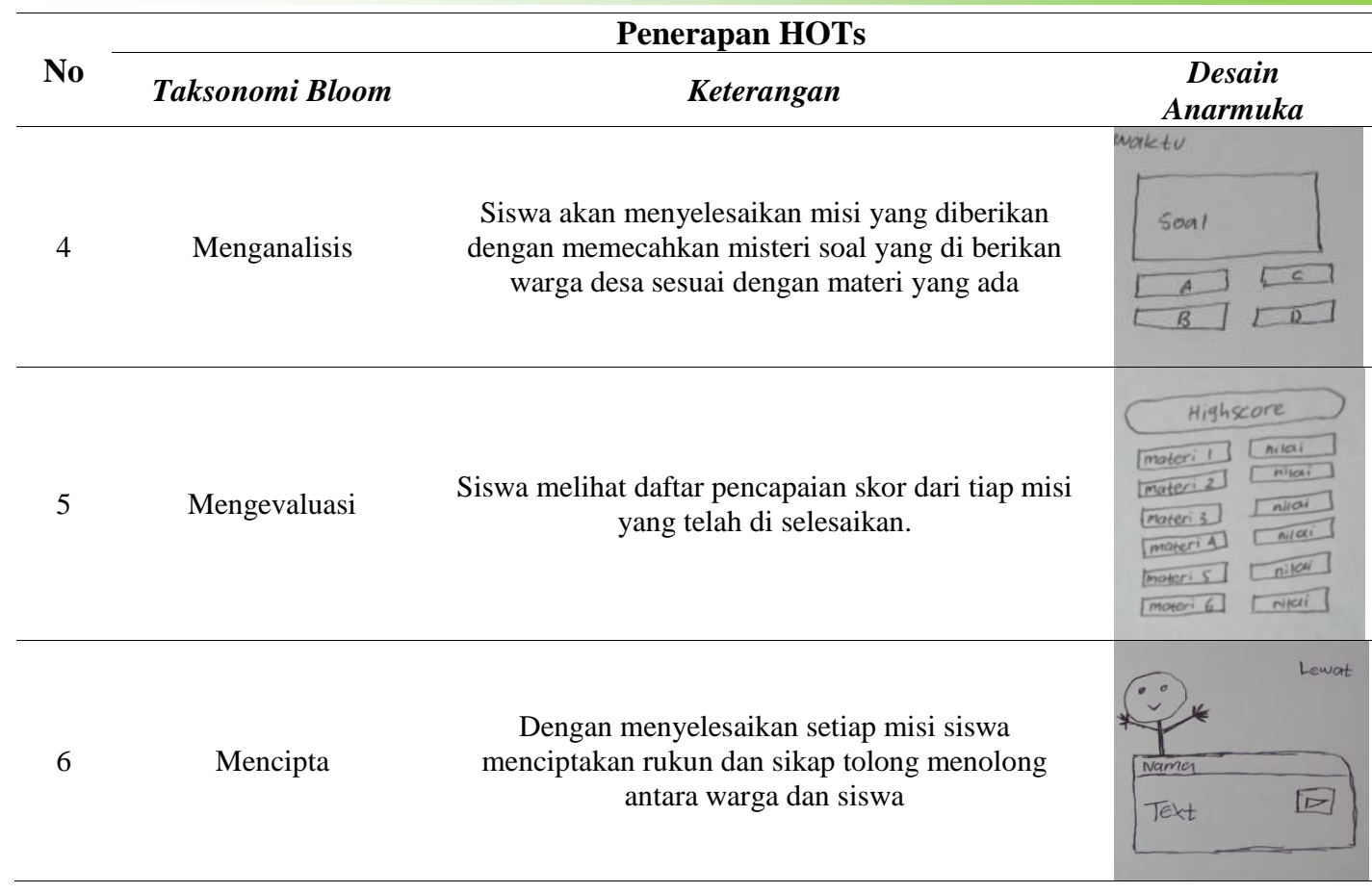

\subsection{Development}

Pembuatan aplikasi permainan menggunakan software Unity, CorelDRAW X7, Adobe Photoshop. Ditahapan ini dilakukan 3 fase yakni:.

- Develop lesson plan for History subject

Dimana player dalam memainkan game ini sedang berjalan-jalan mengelilingi desa yang telah ditentukan, terdapat rumah dan warga disetiap rumah, kemudian didalam rumah terdapat misi atau soal matematika yang harus diselesaikan. Selain itu setiap misi pada setiap rumah selesai maka akan mendapat imbalan berupa skor atau nilai. Berikut adalah tabel materi yang akan dimainkan pemain

- Develop teaching resources

Pembuatan resources diambil dari sumber internet yang menyediakan resources gratis, dan pengeditan pemodelan karakter dan map menggunakan Adobe Photoshop CS dan CorelDraw X7.Berikut tabel resource dari game Petualangan Budi Belajar Matematika

- Develop game prototype

Setelah memperoleh semua data pada tahapan sebelumnya baru tahapan perancangan prototype dikembangkan

\subsection{Quality Assurance}

Tahap pengujiandibagi menjadi 3 tahapan yaitu:

- Check game's quality

Pengujian ini bertujuan untuk menghindari terjadinya bugs pada game maka dilakukan pengujian fungsionalitas pada game sehingga dapat melakukan perbaikan yang diperlukan. Pengujian fungsionalitas game meliputi pengujian terhadap fungsi fitur yang ada di game "Petualangan Budi Belajar Matematika".

- Check game's content

Pengujian dilakukan untuk mengetahui content edukasi didalam game memberikan dampak terhadap user, dalam bentuk survei. Suvei dilakukan terhadap 18 responden anakanak tingkat sekolah dasar kelas 4 dan setiap responden diberikan pertanyaan berkaitan 
dengan game edukasi yang diberikan sebanyak 5 pertanyaan, dan disediakan 5 pilihan yang telah disediakan untuk setiap pernyataannya.

Table 4. Tabel Survei pengujian

\begin{tabular}{|c|c|c|c|c|c|c|}
\hline \multirow{2}{*}{ No } & \multicolumn{6}{|c|}{ Survei Pengujian } \\
\hline & Pernyataan & SS & $\mathbf{S}$ & $\mathrm{CS}$ & TS & STS \\
\hline 1 & Pernyataan 1 & 17 & - & - & - & - \\
\hline 2 & Pernyataan 2 & 11 & 6 & - & - & - \\
\hline 3 & Pernyataan 3 & 9 & 8 & - & - & - \\
\hline 4 & Pernyataan 4 & 13 & 4 & - & - & - \\
\hline 5 & Pernyataan 5 & 13 & 4 & - & - & - \\
\hline & Jumlah & 63 & 22 & - & - & - \\
\hline & Jumlah Skor & 315 & 88 & - & - & - \\
\hline & Skor Observasi & & & 40 & & \\
\hline & Prosentase & & & 94,8 & & \\
\hline
\end{tabular}

Berdasarkan hasil survei didapati hasil indes sebesar 94,82\% maka dapat di simpulkan bahawa setuju bahwa permainan Petualangan Budi Belajar Matematika memberikan pengetahuan dan semangat belajar matematika.

- Implementation and Evaluation

Tahap terakhir adalah implementasi dan evaluasi hasil penelitian, Aplikasi game pembelajaran ini akan didistribusikan kepada siswa kelas 4 SD Negeri 2 Kembangan

\section{Kesimpulan}

Game Petualangan Budi Belajar Matematika untuk anak kelas 4 SD, berbasis android telah berhasil dibuat sebagai game edukasi matematika kelas 4 SD menggunakan metode DGBL-ID dan penerapan HOTs. Dilihat dari hasil dari pengujian tabel 4. yang telah dilakukan dapat ditarik kesimpulan melalui hasil pengujian bahwa game yang dibuat memberikan minat belajar lebih terhadap pembelajaran matematika serta memberikan pemahaman terhadap materi pembelajaran matematika.

\section{Ucapan Terima Kasih}

Ucapan terimakasi kami berikan kepada guru kelas 4 SD Negeri 2 Kembangan yakni Andy Yati yang telah memberikan kesempatan dan dukungan untuk melakukan kegiatan penelitian. Tak lupa kami ucapkan terimakasih dan apresiasinya kepada siswa siswi kelas 4 SD Negeri 2 Kembangan yang telah berpartisipasi dalam kegiatan penelitian ini.

\section{Daftar Pustaka}

[1] N. Sudjana dan A. Rivai, Media Pengajaran. Bandung: Sinar Baru Algesindo, 2001.

[2] U.-U. N. 20, UNDANG-UNDANG NOMOR 20 TAHUN 2003 TENTANG SISTEM PENDIDIKAN NASIONAL, vol. 33, no. 1. Bandung: Citra Umbara Bandung, 2003.

[3] D. I. M.Pd. dan Suparni M.Pd., PEMBELAJARAN MATEMATIKA TEORI DAN APLIKASINYA. Yogyakarta: SUKA PRESS, 2012.

[4] O. Hamalik, "Media Pendidikan.” Citra Aditya Bakti, Bandung, 1994.

[5] Budiyanto dan M. Agus Krisno, Metode Pembelajaran dalam Student Centered Learning. Malang: Universitas Muhammadiyah Malang Press, 2016.

[6] S. Arnab et al., "Mapping learning and game mechanics for serious games analysis," Br. J. Educ. Technol., 2014. 
[7] Soeheri, "DGBL-ID ( Digital Game Based Learning ) Sebagai Arsitektur Perancangan Game Edukasi," EKSPLORA Inform., vol. 6, no. 1, hal. 71-80, 2016.

[8] Y. Yang Carolyn, "Computers \& Education Virtual CEOs : A blended approach to digital gaming for enhancing higher order thinking and academic achievement among vocational high school students," Comput. Educ., vol. 81, hal. 281-295, 2015.

[9] S. Hassan Ruzila, R. Rosli, dan E. Zakaria, "The Use of i-Think Map and Questioning to Promote Higher-Order Thinking Skills in Mathematics," Creat. Educ., vol. 7, no. January, 2016.

[10]D. Shaffer, K. Squire, R. Halverson, dan Gee JP, "Video games and the future of learning," WisconsinMadison Univ., vol. 6, 2014.

[11]S. Rogers, LEVEL UP! The Guide to Great Video Game Design, 1 ed. United Kingdom: WILEY, 2010.

[12]P. Handayani Putri, M. Suyanto, dan H. Al Fatta, "PERANCANGAN GAME DESIGN DOCUMENT SERIOUS GAME PERMAINAN TRADISIONAL ANGKLEK SLEMAN YOGYAKARTA," in Seminar Nasional Informatika, 2015, hal. 1-7.

[13] Doni dan Novaliendry, "Aplikasi Game Geografi Berbasis Multimedia Interaktif (Studi Kasus Siswa Kelas IX SMP N 1 RAO),” J. Teknol. Inf. Pendidik., vol. 6, no. 2, hal. 2, 2013.

[14] S. Waiyakoon, J. Khlaisang, dan P. Koraneekij, "Development of an instructional learning object design model for tablets using game-based learning with scaffolding to enhance mathematical concepts for mathematic learning disability students," Procedia - Soc. Behav. Sci., vol. 174, hal. 1489-1496, 2015.

[15]N. AZAN MAT ZIN, A. JAAFAR, dan W. SENG YUE, "Digital Game-based learning ( DGBL ) model and development methodology for teaching history," WSEAS Trans. Comput., vol. 8, no. 2, hal. 322 333, 2009.

[16] S. Fitri, "The Influence of Digital Games Based Learning o n Students' Learning Outcomes and Motivation," no. March 2013. 